\title{
Nonlinear solutions of lateral response for single pile under the combined action of axial and lateral loads
}

\author{
Kangyu Xing ${ }^{1}$ and Kaishui Zhang ${ }^{1}$ \\ ${ }^{1}$ China University of Geosciences, Engineering Faculty, Wuhan, Hubei 430074, China
}

\begin{abstract}
For the study of the laterally loaded pile under axial load, most of the past research always confined the surrounding soil of pile in the linear elastic and elastic-plastic. In order to consider the nonlinear property of soil around the pile more realistically and improve the design of single piles under combined vertical and lateral loads, a nonlinear analysis method based on the hyperbola p-y curve model is applied to calculate the lateral response of pile. The relevant computer program is developed by MATLAB language, and the relevant solving algorithm is presented. The reliability of this approach was verified through comparisons with the measured data from model tests. The calculation results indicate that the approach was more convenient and accurate than the existing methods. The proposed method is applicable for laterally loaded pile under axial load in preliminary engineering design.
\end{abstract}

\section{Introduction}

For some pile foundations used in marine structures, piles are mainly designed to bear axial and lateral loads, which has drawn more attention of researchers to study the lateral response of pile bearing vertical and horizontal loads. Most studies through the approach including the laboratory tests [1-2], 3D finite-element numerical analyses [3] and also simplified analytic theory to investigate the effect of axial load on lateral loading pile. In the simplified analytic theory, the pile is modelled as a flexible beam and the soil behaviour is represented by different soil-pile load transfer models. And it has the advantages of clear concept and easy application in engineering. The soil-pile load transfer models used in simplified analytic theory can be divided into two types (Fig. 1): linear elastic model [4], and linear elastic-plastic model [5]. Based on the linear elastic model, Zhao et al. [6-7] obtained the power-progression solutions, while Chen et al. [8] obtained the finite difference solutions of the laterally loaded pile under axial load. Based on the elastic-plastic model, Zhang et al. [9] obtained the elasticplastic solutions, in which the ultimate resistance of soil was taken into account.

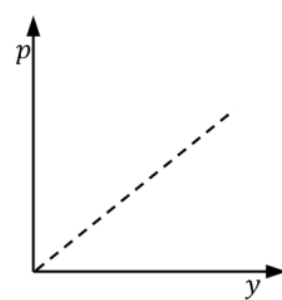

(a). Linear elastic model

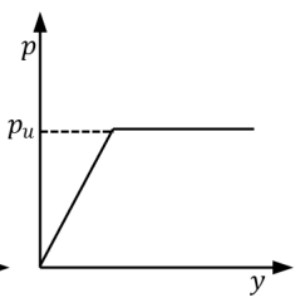

(b). Elastic-plastic model
Fig. 1 Load Transfer Model of Soil-Pile Interaction
However, the soil-pile interaction cannot be simply modelled by linear elastic model when the pile shaft bears a large lateral load because of the nonlinear property of soil. The linear elastic model and linear elastic-plastic model can't consider the nonlinear property of soil around the pile. For the lateral loading pile, Kim et al. [10] obtained the hyperbola p-y curve model, in which the nonlinear property of soil was considered. However, the calculation of the single pile under combined axial and horizontal loads with the hyperbola p-y curve model, has less been mentioned in the correlational studies so far.

This work aims to present a numerical solution for vertical and horizontal loading piles with hyperbola p-y curve model based on the finite difference method. The validity of the proposed method is verified by comparing with the test dates and existing methods in literature.

\section{The establishment and solution of equations}

The analysis model of this paper is schematically described in figure 2 . The single pile bearing vertical and horizontal loads has the following parameters: length $L$, diameter $d$, and bending stiffness $E I$. The pile length at free zone and embed zone is $L_{a}$ and $L_{e}$, respectively. The horizontal force $H_{0}$, moment $M_{0}$, and axial load $V_{0}$ act on the pile head, respectively. In this study, the load transfer model of soil-pile interaction is modelled by nonlinear springs distributed along the pile shaft. Assume that the axial load has no influence at the ability of the pile to resist lateral deformation and the calculation of shear force, moment, and deflection of pile shaft follow the traditional elastic foundation beam model. According to

\footnotetext{
*Corresponding author: Xing_kangyu@163.com; 1105669075@qq.com
} 
the bending theory of beams, the differential equation of the pile above and below the ground are:

$$
\left\{\begin{array}{l}
E I \frac{\mathrm{d}^{3} y_{a}}{\mathrm{~d} z_{a}^{3}}+N_{a} \frac{\mathrm{d} y_{a}}{\mathrm{~d} z_{a}}=H_{0} \\
E I \frac{\mathrm{d}^{4} y_{e}}{\mathrm{~d} z_{e}{ }^{4}}+N_{e} \frac{\mathrm{d}^{2} y_{e}}{\mathrm{~d} z_{e}{ }^{2}}+\frac{\mathrm{d} N_{e}}{\mathrm{~d} z} \frac{\mathrm{d} y_{e}}{\mathrm{~d} z_{e}}+p=0
\end{array}\right.
$$

Where $y_{a}$ and $y_{e}$ denote the lateral deflection of the pile at depth $z_{e}$ and $z_{a}$, respectively; $p$ denote soil resistance; $\quad N\left(z_{e}\right)=V_{0}+A_{p} \gamma_{p} z-\frac{1}{2} K_{0} \gamma_{s}\left(z_{e}\right)^{2} u \tan \delta$ denotes the vertical forces along pile body below ground surface; $A_{p}, \gamma_{p}, K_{0}, u$, and $\delta$ denote the crosssectional area, unit weight of the pile, coefficient of static earth pressure, perimeter of pile shaft and soil-pile contact friction angle; $N_{a}=V_{0}+A_{p} \gamma_{p} z_{a}$ denotes the vertical forces along pile body above ground surface.

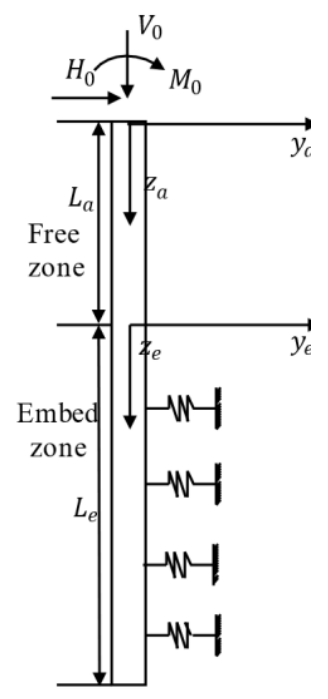

Fig. 2 Schematic diagram of pile under combined loading

The finite difference method is utilized to solve equation (1). Figure 3 illustrates the discretization of pile. The pile above and below ground surface are divided into $n_{1}+1$ and $n_{2}+1$ elements of length $h\left(h=L /\left(n_{1}+n_{2}\right)\right.$, $\left.n=n_{1}+n_{2}\right)$, respectively. Figure 2(a) and 2(b) include extra 2 virtual elements at the two ends of the pile, respectively. Correspondingly, equation (1) can be written in the finite difference form:

$$
\left\{\begin{array}{l}
y_{a(i+2)}+\varphi_{i} y_{\mathrm{a}(i+1)}-\varphi_{i} y_{a(i-1)}-y_{a(i-2)}=2 H_{0} h^{3} / E I \\
y_{e(j+2)}+\phi_{j} y_{e(j+1)}+\omega_{j} y_{e j}+\psi_{j} y_{e(j-1)}-y_{e(j-2)}+p_{j} h^{4} / E I=0
\end{array}\right.
$$

Where $y_{a(i)}$ and $y_{e(j)}$ denote displacement of $i$ th and $j$ th pile element; $\psi_{j}=-4+\frac{N_{e j} h^{2}}{E I}-\frac{\mathrm{d} N_{e j} h^{3}}{2 E I}$ $\varphi_{i}=\frac{N_{a(i)} h^{2}}{E I}-2 \quad ; \quad \phi_{j}=-4+\frac{N_{e j} h^{2}}{E I}+\frac{\mathrm{d} N_{e j} h^{3}}{2 E I} \quad ;$ $\omega_{e(j)}=6-\frac{2 N_{e j} h^{2}}{E I}$.

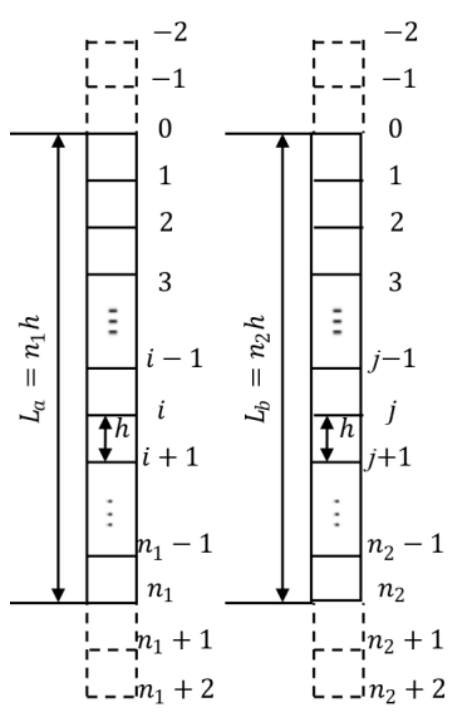

(a)free zone (b)embed zone

Fig.3 discretization analysis of pile

Based on the model test, Kim [10] established the hyperbolic load transfer model, as shown in figure 4 . Accordingly, $p_{j}$ in equation (2) can be calculated according to the following formula:

$$
p_{j}=\frac{y_{e(j)}}{\frac{1}{k_{i n j}}+\frac{y_{e(j)}}{p_{u j}}}
$$

where $k_{i n j}=\eta_{h} z_{e(j)}$ denotes initial horizontal subgrade modulus; $\eta_{h}$ denotes subgrade coefficient that depends on relative density of soil[11]; $p_{u j}$ denotes the ultimate soil-pile reaction and. $p_{u j}=N_{g} \gamma_{s} d^{2-n}\left(\alpha_{0}+z_{e(j)}\right)^{n}$ denotes [12] the ultimate soil-pile reaction; $\gamma_{\mathrm{s}}$ denotes unit weight of soil. The values of other parameters are as follows: for piles in clay, $\alpha_{0}=0 ; n=1.7$, $N_{\mathrm{g}}=(0.55 \sim 2.5) K_{p}{ }^{2} ;$ For piles in sand, $\alpha_{0}=0 \sim 0.4$; $n=0.36 \sim 1.0 ; N_{\mathrm{g}}=(0.4 \sim 1.6) K_{p}{ }^{2}, K_{p}=$ coefficient of passive earth pressure.

Eq. (3) is widely used in stress-strain soil problems and was also found to fit remarkably well to the relationship between soil resistance and displacement [13].

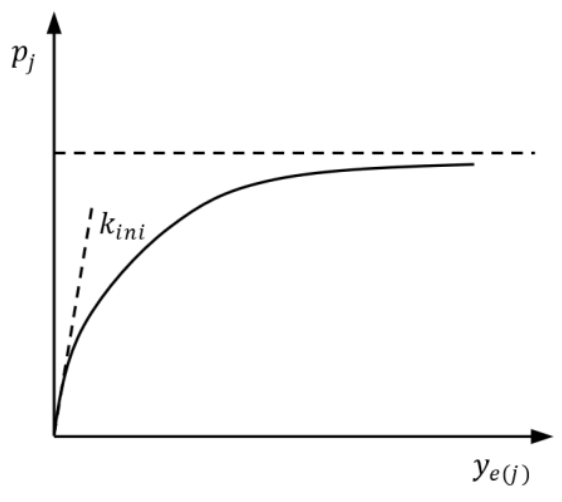

Fig. 4 Load Transfer Model of Soil-Pile Interaction 


\subsection{The solution of the differential equation}

The pile bottom and pile top boundary conditions must be confirmed to solve equations (2). For the free-top condition, the periphery condition at the pile top is $M_{a(0)}=0$. Combining the finite difference method, the periphery condition at the pile top is presented as:

$$
y_{a(-1)}-2 y_{a(0)}+y_{a(1)}=\frac{h^{2}}{E I} M_{0}
$$

For the free-bottom condition, the periphery conditions at the pile bottom are $M_{e\left(n_{2}\right)}=Q_{e\left(n_{2}\right)}=0$. Similarly, the periphery conditions at the pile bottom is presented as:

$$
\left\{\begin{array}{l}
y_{e\left(n_{2}-1\right)}-2 y_{e\left(n_{2}\right)}+y_{e\left(n_{2}+1\right)}=0 \\
y_{e\left(n_{2}-2\right)}+\varphi_{n_{2}} y_{e\left(n_{2}-1\right)}-\varphi_{n_{2}} y_{e\left(n_{2}+1\right)}-y_{e\left(n_{2}+2\right)}=0
\end{array}\right.
$$

Using the continuity conditions, we can obtain the four deflection of virtual points at the ground interface. According to the continuity conditions, the deflection, rotation, moment, and shearing force of pile free zone and pile embedded zone is equivalent. The continuity conditions can be expressed as:

$$
\begin{aligned}
& y_{a\left(n_{1}\right)}=y_{e(0)}, y_{a\left(n_{1}-1\right)}=y_{e(-1)}, y_{a\left(n_{1}-2\right)}=y_{e(-2)} \\
& y_{a\left(n_{1}+1\right)}=y_{e(1)}, y_{a\left(n_{1}+2\right)}=y_{e(2)}
\end{aligned}
$$

Combining with the Eq. (2) at each node and boundary conditions (4), the nonlinear difference equations $F(\mathbf{Y})$ can be obtained. Its matrix form is as follows:

$$
F(\mathbf{Y})=[K]\{\mathbf{Y}\}+\{P\}+\{C\}=0
$$

Where $\{\mathbf{Y}\}=\left\{y_{a(-2)}, \ldots ., y_{a\left(n_{1}\right)}, y_{e(0)}, \ldots ., y_{e\left(n_{2}+2\right)}\right\}^{T}$ is a $n+5$ pile deflection vectors; $[K]$ is a $(n+5) \times(n+5)$ pile stiffness matrix; $\{P\}$ and $\{C\}$ are $n+5$ resistance of each soil layer and loading vectors, respectively; The coefficients in the matrix $[K]$ are given as follow: $[K]_{1,2}=1,[K]_{1,3}=-2,[K]_{1,4}=1,[K]_{i, i-1}=-1,[K]_{i, i}=-\varphi_{i}$, $[K]_{i, i+2}=\varphi_{i} \quad,[K]_{i, i+3}=1 \quad,\left(2 \leq i \leq n_{1}+2\right) \quad ; \quad[K]_{i, i-2}=1$, $[K]_{i, i-1}=\psi_{i-n_{1}-2},[K]_{i, i}=\omega_{i-n_{1}-2},[K]_{i, i+1}=\phi_{i-n_{1}-2},[K]_{i, i+2}=1$, $\left(n_{1}+3 \leq i \leq n+3\right) \quad ; \quad[K]_{n+4, n+1}=-1 \quad,[K]_{n+4, n+2}=-\varphi_{n+3}$ ， $[K]_{n+4, n+4}=\varphi_{n+3},[K]_{n+4, n+5}=1,[K]_{n+5, n+2}=1,[K]_{n+5, n+3}=-2$, $[K]_{n+5, n+4}=1$; The rest of coefficients is zero. The vectors $\{P\} \quad$ can be expressed as: $\{P\}=\left\{0, \cdots, 0,\left(h^{4} / E I\right) p_{0}, \cdots,\left(h^{4} / E I\right) p_{n_{2}}\right\} \quad$. The vectors $\{C\}=\left\{2 H_{0} h^{3} / E I, \cdots, 2 H_{0} h^{3} / E I, 0, \cdots 0\right\}$.

It is difficult to solve equations (6) analytically. So, the Newton iteration method [14] is used in this work. The relevant computational program has developed using MATLAB [15] language and the following algorithm to calculate $\{\mathbf{Y}\}$ is presented:

(1) Input the basic pile and soil parameters. Combine the equations (2) (4) to obtain the nonlinear equations $F(\mathbf{Y})$, and get the Jacobi matrix of equations $F^{\prime}(\mathbf{Y})$ $\left(F^{\prime}(\mathbf{Y})=\left(\partial_{i} f_{i}(\mathbf{Y})\right)_{(n+5) \times(n+5)} \quad\right)$. Assume the initial approximate solution $\left\{\mathbf{Y}^{0}\right\}$ and convergence criteria $\varepsilon$.

(2) Setting $\mathrm{k}=0$, solve the equations (7) to obtain $\left\{\Delta \mathbf{Y}^{k}\right\}$ :

$$
F^{\prime}\left(\mathbf{Y}^{k}\right)\left\{\Delta \mathbf{Y}^{k}\right\}+F\left(\mathbf{Y}^{k}\right)=0
$$

(3) Check if $\left\|\left\{\Delta \mathbf{Y}^{k}\right\}\right\| \geq \varepsilon$, setting $\left\{\mathbf{Y}^{k+1}\right\}=\left\{\mathbf{Y}^{k}\right\}+\left\{\Delta \mathbf{Y}^{k}\right\}$ and $k=k+1$, then return to the step (2). If $\left\|\left\{\Delta \mathbf{Y}^{k}\right\}\right\| \leq \varepsilon$, setting $\left\{\mathbf{Y}^{*}\right\}=\left\{\mathbf{Y}^{k}\right\}$, then output the vector $\left\{\mathbf{Y}^{*}\right\}$ of pile and go to step (4).

(4) According to the displacement vector $\left\{\mathbf{Y}^{*}\right\}$ of pile, the bending moment along the pile can be also obtained:

$$
\{M\}=\frac{E I}{h^{2}}\left\{\mathbf{Y}^{*}\right\}
$$

In order to simplify the calculation process, it is noteworthy that the initial approximate solution $\left\{\mathbf{Y}^{0}\right\}$ can be replaced by results of linear-elastic method. If choose the line-elastic or elastic-plastic model to calculate the soil resistance, it is noteworthy that the nonlinear equations will become a linear equations. It can be solved by matrix operate to obtain the pile response.

\section{Validation}

Zhao [16] carried out a series of laboratory model pile tests under vertical and horizontal loading. The diameter of the pile is $0.016 \mathrm{~m}$. Two groups of test are selected to verify the convenient and accurate of proposed method. Test 1: the pile length is $1 \mathrm{~m}$, the embedment depth is $0.78 \mathrm{~m}$, the pile bending stiffness is $0.143 \mathrm{kN} \cdot \mathrm{m}^{2}$, $V_{0}=0.0415 \mathrm{kN}$, and $H_{0}=0.0719 \mathrm{kN}$. The unit weight and internal friction angle of homogeneous medium sand are $15.4 \mathrm{kN} / \mathrm{m}^{3}$ and $36^{\circ}$, respectively. Test 2 : the length of the pile is $0.9 \mathrm{~m}$, the embedment depth is $0.695 \mathrm{~m}$, the pile bending stiffness is $0.19 \mathrm{kN} \cdot \mathrm{m}^{2}, V_{0}=0.1008 \mathrm{kN}$, and $H_{0}=0.192 \mathrm{kN}$. The unit weight and internal friction angle of homogeneous medium sand are $16.8 \mathrm{kN} / \mathrm{m}^{3}$ and $37^{\circ}$, respectively. It is noted that pile unit weight is small enough to be neglected in this calculation[i.e., $\gamma_{p}=0$ ]. In this calculation, the following soil parameters are used: $\eta_{h}=7000 \mathrm{kN} / \mathrm{m}^{3}$ in the test $1, \eta_{h}=10000 \mathrm{kN} / \mathrm{m}^{3}$ in the test 2. The pile bending moment comparison of this work prediction results with test results are shown in figure 5 . The results show that the pile bending moment embedded death predicted by the proposed method are consistent with the model test results.

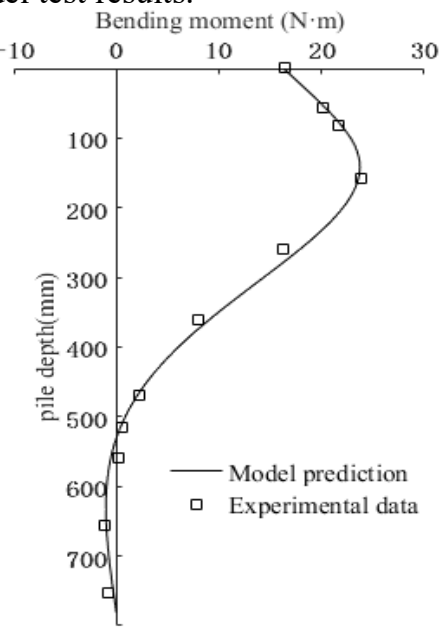

(a) test 1 


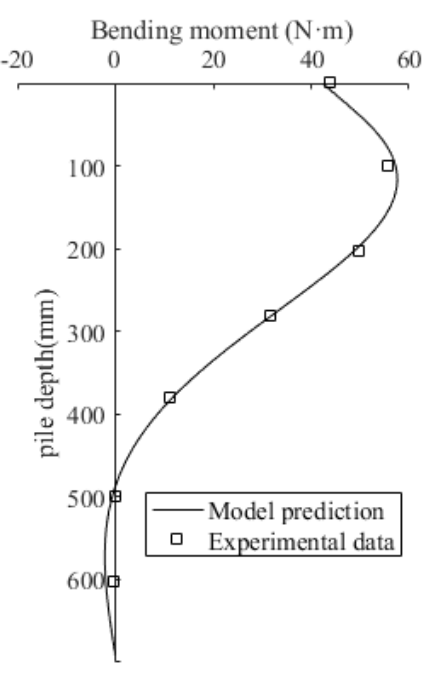

(b) test 2

figure 5. Bending moment comparison of this work prediction results with model pile test results

The comparisons between the calculated dates using different load transfer models and measured dates in test 1 are shown in table 1 . It could be found that the results of this paper and elastic-plastic model were similar with the test result, while the results with Linear-elastic model have a larger error. The Linear-elastic model is based on the elastic deformation thesis of soil, and it is only suitable to the small deformation of pile. This phenomenon can be explained by the characteristics of the hyperbola $p-y$ curve model. The hyperbola p-y curve model used in this paper can consider the plastic and nonlinear deformation of surrounding soil of pile. Therefore, it is suitable to the situation of the large deformation.

Table 1 Comparisons between the calculated date and measured date in test 1

\begin{tabular}{ccc}
\hline Methods & $\begin{array}{c}\text { Sand surface } \\
\text { displacement } \\
(\mathrm{mm})\end{array}$ & $\begin{array}{c}\text { maximum } \\
\text { bending } \\
\text { moment }(\mathrm{N} \cdot \mathrm{m})\end{array}$ \\
\hline This paper & 8.8237 & 23.1462 \\
Elastic-plastic[6] & 8.6704 & 23.0232 \\
Linear-elastic[4] & 7.1384 & 20.603 \\
Measured data & 8.771 & 22.3 \\
\hline
\end{tabular}

\section{Conclusion}

Using the nonlinear analysis method based on the hyperbola p-y curve model, a generalized numerical solution of single pile bearing vertical and horizontal loads were presented. The method of this paper were verified by comparing the calculated value with laboratory model tests results. These prediction dates given by the proposed method were close to the results from laboratory models. Finally, the effect of the nonlinear solution was analysed on the lateral response for pile by comparing computed results from different load transfer models and measured dates. It was clear that the proposed approach based on the hyperbola p-y curve model can reflect the nonlinear characteristic of soil conveniently and accurately.

\section{References}

1. Suits, L. D., Sheahan, T. C., Lee, J., Prezzi, M., \& Salgado, R. Experimental investigation of the combined load response of model piles driven in sand. Geotechnical Testing Journal, 34(6), 103269. (2011).

2. Sastry, V. V. R. N., \& Meyerhof, G. G. Behaviour of flexible piles in layered sands under eccentric and incli. International Journal of Rock Mechanics \& Mining Science \& Geomechanics Abstracts, 32(4), 161A-161A. (1995).

3. Karthigeyan, S., Ramakrishna, V. V. G. S. T., \& Rajagopal, K. Numerical investigation of the effect of vertical load on the lateral response of piles. Journal of Geotechnical \& Geoenvironmental Engineering, 133(5), 512-521. (2007).

4. Reese, L., Van I, W., \& Holtz, R. Single piles and pile groups under lateral loading. Applied Mechanics Reviews, 55(1), B9-B10. (2002).

5. Hsiung, Y. M., Chen, S. S., \& Chou, Y. C. Analytical solution for piles supporting combined lateral loads. Journal of Geotechnical \& Geoenvironmental Engineering, 132(10), 1315-1324. (2006).

6. Zhao, M. Calculation of the pile foundation both under lateral and vertical load[J]. Journal of Hunan University.14(2), 66-81. (1987). (In Chinese)

7. Zhao, M., Xu Z, Ma B, et al.. Power series solution for pile based on C-method under inclined loads[J]. Journal of Hunan University: Natural Science, 39(3), 1-5. (2012) (In Chinese)

8. Chen L., Yu Q., \& Dai Z. Finite difference solution based on composite stiffness and bi-parameter method for calculating vertical and horizontal bending piles. Journal of rock mechanics and engineering, 35 (3), 613-622. (2016). (In Chinese)

9. Zhang L., Gong X., \& Yang Z. Elastoplastic solutions for single piles under combined vertical and lateral loads. Journal of Central South University of Technology, 18(1), 216-222. (2011).

10. Kim, B. T., Kim, N. K., Lee, W. J., \& Kim, Y. S. Experimental load-transfer curves of laterally loaded piles in nak-dong river sand. Journal of Geotechnical \& Geoenvironmental Engineering, 130(4), 416-425. (2004).

11. American Petroleum Institute. Geotechnical and Foundation Design Considerations. ANSI/API Recommended Practice 2 GEO (2014).

12. GUO W D, LEE F H. Load transfer approach for laterally loaded piles[J]. International Journal for Numerical and Analytical Methods in Geomechanics, 25(11): 1101-1129. (2001).

13. Kondner, R. L. Hyperbolic stress-strain response: cohesive soils. Journal of the Soil Mechanics \& Foundations Division, 89(1), 115-143. (1963).

14. Li Q. Numerical method for solving nonlinear equations [M]. Beijing: science press. (2005) (In Chinese) 
15. MATLAB [Computer software]. MathWorks, Natick, MA.

16. Zhao, M. Study on the Behavior of Piles under Inclined Loads[D] (2001). (Doctoral dissertation, hunan university). 